\title{
Dynamic formation process of thick deformation zone on the shallow plate boundary fault of the Japan Trench: insight from analog experiments of half-graben subduction
}

\author{
Hiroaki Koge ${ }^{1,2,3^{*}}$ D, Yasuhiro Yamada ${ }^{3,4}$, Akihiro Ohde ${ }^{1}$, Arthur Bauville ${ }^{3}$, Asuka Yamaguchi ${ }^{1}$ and Juichiro Ashi ${ }^{1,2}$
}

\begin{abstract}
The 2011 Tohoku-oki earthquake unexpectedly ruptured to the shallowest portion of the plate boundary fault and triggered a large tsunami. The shallow portion had generally been regarded as a seismically stable zone until this event, but its significance has now been dramatically revealed for future disaster mitigation. This research approaches the shallow portion, especially the formation process of its structure and plate boundary faults. Scientific drilling conducted near the Japan Trench after the earthquake reported a thin plate boundary fault $(\sim 7 \mathrm{~m})$ and thick deformation zone $(\sim 100 \mathrm{~m})$. This thin fault would be expected given the relatively small displacement near the trench $(\sim 3.2 \mathrm{~km})$, but the deformation zone thickness is anomalously wide given this small magnitude of slip. To understand the dynamic deformation processes that lead to the development of a thick deformation zone surrounding a thin fault core, we conducted forward modeling of an analog experiment with the technique to visualize fault activity. Sandbox experiments are effective for the approximation of the geological phenomenon and structure. The seismic profile of the largest slip region in the 2011 earthquake shows that a half-graben structure has been subducted underneath the frontal wedge, thus we focused on this structural architecture. As a result, we found a new fault formation pattern, i.e., the frontal thrust (the most frontal part of décollement) periodically partitioned into pieces, which connect again to form a large-continuous fault. The fault also oscillates up and down during this process, which we call "dancing," and a thick shear zone is formed in a relatively short time where this occurs, even though the fault only has a small displacement. By analogy, the thick deformation zone observed at the Japan Trench could be formed by such fault dancing. The energy of the fault activity is commonly estimated from the fault displacement derived from the thickness of the shear zones. Applying the thickness-displacement law without considering the effect of the dancing may cause overestimation. The architecture of the shear zone formed is similar to that of a mélange, and the origin of tectonic mélanges may be explained by this mechanism.
\end{abstract}

Keywords: Analog model, Digital image correlation, Japan Trench, Sandbox, Thrust formation

\footnotetext{
* Correspondence: koge@aori.u-tokyo.ac.jp

'Atmosphere and Ocean Research Institute, The University of Tokyo, 5-1-5 Kashiwanoha, Kashiwa-shi, Chiba 277-8564, Japan

${ }^{2}$ Department of Natural Environmental Studies Division of Environmental

Studies, Graduate School of Frontier Sciences, The University of Tokyo, 5-1-5

Kashiwanoha, Kashiwa-shi, Chiba 277-8564, Japan

Full list of author information is available at the end of the article
} 


\section{Introduction}

Recently, the study of shallowest part of subduction plate boundary faults has become the frontier of research into fault rupture processes. Until the 2011 Tohoku-oki earthquake, the shallow portion of the plate boundary fault in the subduction zone (near the trench axis area, or under the frontal wedge) had generally been regarded as a seismically slip zone (Bilek and Lay 2002), with low levels of locking (e.g., Scholz 1998). However, the fault rupture extended to the trench axis during the 2011 Tohoku-oki earthquake, and its coseismic displacement of up to approximately $60 \mathrm{~m}$ near the trench axis resulted in the huge tsunami that devastated much of the east coast of Japan (e.g., Fujiwara et al. 2011; Kodaira et al. 2012; Sun et al. 2017). The evolution and fault mechanics in the shallow portion of the subduction zone became an important region in disaster mitigation. To understand the detailed features (e.g., the structure or physical properties) of the fault near the trench axis, a scientific rapid-response drilling was conducted 1 year after the earthquake; the JFAST (Japan Trench Fast Drilling Project). This project, consisting of two IODP (Integrated Ocean Drilling Program) cruises (Expedition 343 and 343T), obtained limited core samples and continuous geophysical logging data that show two major faults at $\sim 720$ and $\sim 820$ mbsf (Fig. 1).

Core sample observations suggest that the fault zone at 820 mbsf is very likely the plate boundary, which has a limited thickness of less than $\sim 7 \mathrm{~m}$ (Kirkpatrick et al. 2015) and is composed of frictionally weak materials (Ujiie et al. 2013). The seismic profile across the drill site, logging data, and bedding dips in cores show that the $100 \mathrm{~m}$ interval between the two faults corresponds to a structurally complex and acoustically chaotic zone (Chester et al. 2012; Nakamura et al. 2013) (Fig. 1), hereafter referred to as "deformation zone" in this paper. Such a complex structure near the deformation front is surprising because frontal prism structures are generally clearly imaged in seismic data from other areas, e.g., Sumatra (Moeremans et al. 2014) and Nankai (Moore et al. 1990). At the JFAST drill site, the total horizontal displacement of the plate boundary fault is estimated to be $3.2 \mathrm{~km}$ (Chester et al. 2013). Since the relative rate of plate

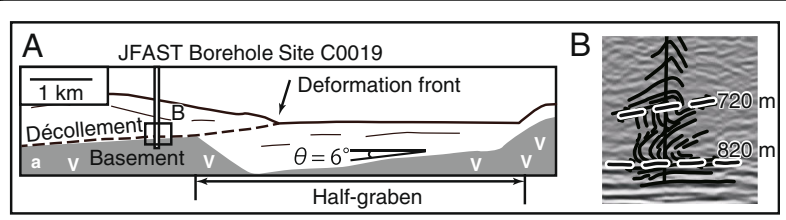

Fig. 1 a Interpretation of a seismic reflection profile before the 2011 earthquake (Kodaira et al. 2012). b Apparent dip of bedding in the in-line seismic section derived from borehole LWD resistivity images across the plate boundary through the fault zone (Chester et al. 2012) motion is $97.1 \mathrm{~mm} /$ year based on the MORVEL plate motion model (DeMets et al. 2010), this displacement is only equivalent to the plate convergence of 0.03 million years. There is discrepancy that such a short duration may not be enough to construct the $100 \mathrm{~m}$ thick deformation zone. For comparison, the thickness of the deformation zone of Nankai Trough which is more typical for the shallow subduction thrusts is notable less than $\sim 50 \mathrm{~m}$ (Kirkpatrick et al. 2015). This study focuses on this discrepancy in the Japan Trench, which may be important in understanding the formation process of a relatively wide deformation zone in the shallow portion of the subduction zone of the Japan Trench. In order to understand the dynamic formation/deformation process of the frontal structure, we used a forward modeling method that combines analog sandbox experiments and the digital image correlation (DIC) technique. Most previous experiments used a flat basement to model the subducting plate (see review by Graveleau et al. 2012), but in the Japan Trench, there is a subducting half-graben structure underneath the frontal wedge, according to the seismic profile across the largest slip region in the 2011 earthquake at the latitude of the JFAST drill site (Kodaira et al. 2012; Chester et al. 2012). We therefore examined the effects of subduction of the half-graben structure on décollement evolution.

\section{Methods/Experimental}

Physical experimentation using analog materials is a useful technique to visualize the geometry and deformation processes of accretionary prisms (Graveleau et al. 2012). In order to reconstruct large-scale geological structure, such as accretionary prism in laboratory, we need to use cohesionless material. The reason is that non-cohesive granular materials draws stress-strain curves similar to that of natural rocks (Lohrmann et al. 2003). With a general brittle scaling of cohesionless sand under the length ratio $10^{-4}$ to $10^{-5}$, a $1 \mathrm{~cm}$ model layer in an experiment generally corresponds to $100 \mathrm{~m}$ to $1 \mathrm{~km}$ of sedimentary strata in nature. We used Toyoura sand as our experimental material to simulate the brittle deformation at the Tohoku frontal wedge. Toyoura sand, a cohesionless quartz sand with a 106-300 $\mu \mathrm{m}$ grain size, and a dynamic frictional coefficient of $\sim 0.589$ and density of $1.602 \mathrm{~g} / \mathrm{cm}^{3}$, is one of the standard materials for civil engineering purposes in Japan (JIS R 5201). The dynamic frictional coefficient of Toyoura sand on the basal shear zone is $\sim 0.218$ (Dotare et al. 2017). In this study $1 \mathrm{~cm}$ in the model corresponds to $230 \mathrm{~m}$ in nature. The experiment is coupled with DIC, which allows one to visualize the velocity field and thus visualize fault activities within a deforming sand body (Adam et al. 2005). The experimental setup consists of a box of $25 \times 90 \times 30 \mathrm{~cm}$ (height, length, and width, respectively) with a moving wall, side-glass panes, and a Teflon-surfaced basement (Fig. 2a). Since Teflon has low 

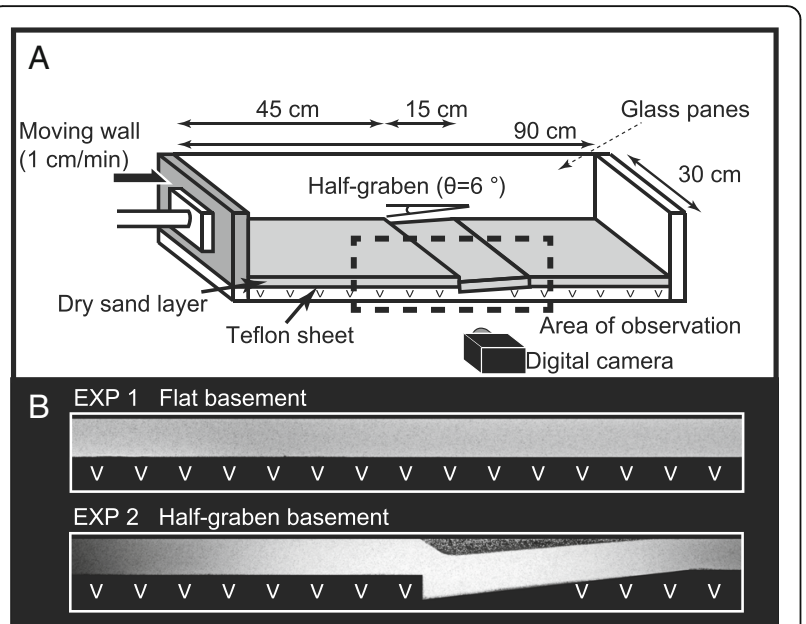

Fig. 2 Outline of sandbox apparatus under initial conditions. a Diagram of our experimental apparatus. Dry sands were filled on the basement surface pasted by a Teflon sheet. The right wall was fixed, and the left side wall was displaced at a uniform speed $(1 \mathrm{~cm} / \mathrm{min})$. The $2 \mathrm{D}$ deformation around the half-graben structure area was continuously recorded with a digital camera and analyzed to visualize the deformation, especially fault activity. b Photographs showing initial setup of the analog experiments for half-graben basement without trench-fill (EXP 2), and flat basement reference model (EXP 1)

friction, shear is generated on this surface. For all experiments, the initial sand thickness was $2 \mathrm{~cm}$. The slope angle in the half-graben was set at $6^{\circ}$, which corresponds to observations around the JFAST site (Fig. 2a). The sand layer was deformed by the moving wall, which was controlled by the motor at the constant speed of $1 \mathrm{~cm} / \mathrm{min}$ in order to maintain quasi-static conditions. During the experiments, the deformation was photographed through the side glass pane by a digital camera for DIC, and we visualized shear strength as the fault activity (LaVision 2012). We conducted the experiments under two conditions: EXP 1: a flat basement reference model; and EXP 2: a half-graben basement without trench-fill (Fig. 2b). The experimental basement structure of EXP 2 was based on the seismic profile of Kodaira et al. (2012), and the condition of the sediments was based on Fig. S2-A of Chester et al. (2013). The slope portion of the basement could be moved from the flat to inclined position. The configuration of the half-graben model (EXP 2) was constructed by tilting the basement after the sand distribution (Fig. 2b, EXP 2). The flat basement experiment was conducted (Fig. 2b, EXP 1) for comparison.

Conventional sandbox experiments require marker layers to visualize the deformation of the initial structure, but the insertion of markers causes two problems. One is the difficulty of uniform preparation of sand layers, and the other is the effect of layer parallel slip along marker layers. DIC eliminates the above problems and allows us to use a single substance. In this research, the resolution of DIC is $0.08 \mathrm{~mm} \approx 1$ pixel. We used a custom-made sand-distributer, which automatically produces a homogeneous layer of sand (e.g., Dotare et al. 2017). Thus, it was possible to minimize heterogeneity in the initial layers and conduct experiments with almost the same condition every time throughout the study.

\section{Results}

Shortening produced localized slip at the bottom of the moving wall along the basement surface in both experiments. The flat basement reference model (EXP 1) progressively formed a frontal wedge with an approximately constant interval of spacing $8.42 \mathrm{~cm}$ (Fig. 3). The frontal wedge consisted of a series of symmetric pop-up structures, which were a combination of a fore thrust and back thrust (e.g., McClay 1992). The fluctuation phenomena, the heterogeneous reactivation of thrust systems in the wedge (e.g., Yamada et al. 2014), was also observed in this experiment.

The half-graben model (EXP 2) produced sequential deformations, which can be characteristically divided into four stages (Fig. 4). In stage 1 (15.80-17.97 cm of shortening), the fore thrust T2 was formed with a long interval distance $(12.79 \mathrm{~cm})$ at the half-graben, compared to the interval $(8.42 \mathrm{~cm})$ of EXP 1 . In stage $2(17.97-20.14 \mathrm{~cm}$ of shortening), a pair of out-of-sequence thrusts (OST) T3 with its conjugate fault T3' formed with a pop-up structure (e.g., McClay 1992) between these thrusts. In stage 3

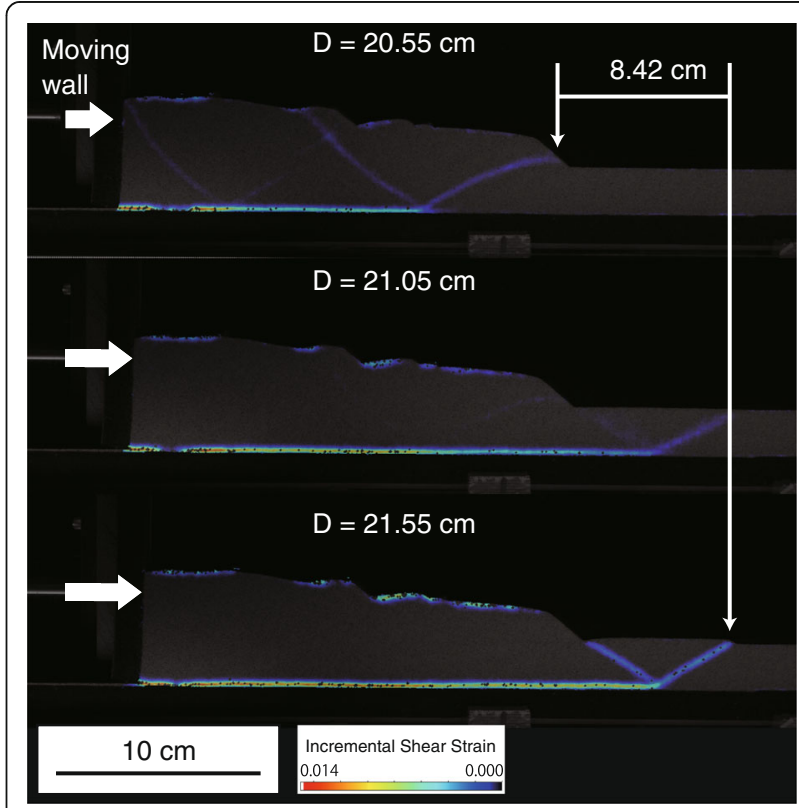

Fig. 3 Deformation timeline with convergence of flat basement reference model (EXP 1). The shortening (D) increases from the top to the bottom. The incremental shear strain becomes larger in the order from blue to red in the color reference. Incremental shear strain indicates not absolute magnitude, but relative 


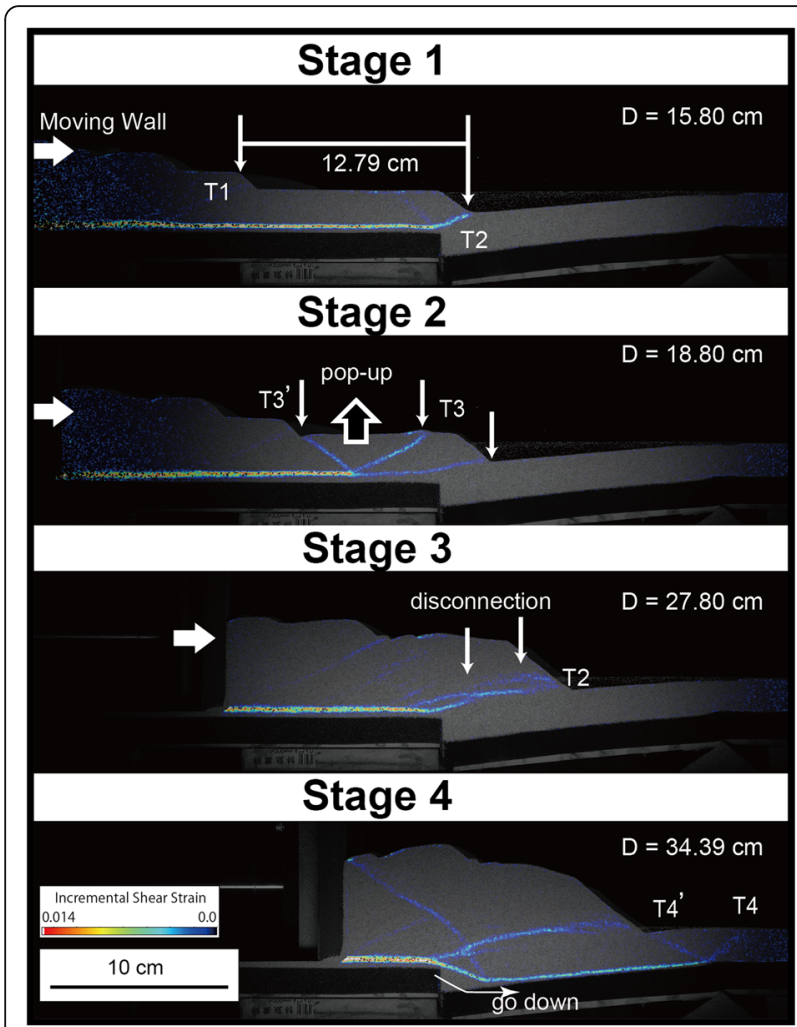

Fig. 4 Deformation timeline with convergence of half-graben

basement without trench-fill (EXP 2). The shortening (D) increases from the top to the bottom. The incremental shear strain becomes larger in the order from blue to red in the color reference. Incremental shear strain indicates relative, not absolute, quantity

(20.14-32.80 cm of shortening), the most frontal part of the décollement periodically partitioned into pieces, which connected again to form a large-continuous fault. The fault also oscillated up and down during this process. We call this dynamic faulting phenomenon "dancing," and describe it in detail below. In stage $4(32.80 \mathrm{~cm}$ of shortening and beyond), the plate boundary faults extended down to the basement surface of the half-graben structure, and the new thrust T4 developed. T2 stopped dancing, but it remained active concurrent with slip on T4. The dancing phenomenon was observed for a relatively long time, and thus the length of stage 3 continued from $20.14 \mathrm{~cm}$ to $32.80 \mathrm{~cm}$ of shortening. A snapshot of the dancing phenomenon exhibited an anastomosing fault structure. The dancing T2 fault was initially short with simple strait geometry (Fig. $5 \mathrm{a}-\mathrm{c}$ ), and began bending, convex upwards, as the shortening progressed (Fig. 5a, b). Then, a new straight fault was generated in the footwall to shortcut beneath the bent part of the fault (Fig. 5b, c). Then, the bent part of the fault ceased activity. The straight fault then also started bending as shortening progressed, and the same action occurred repeatedly afterwards. During the initial stage of dancing, the branch point (the root of the T2)

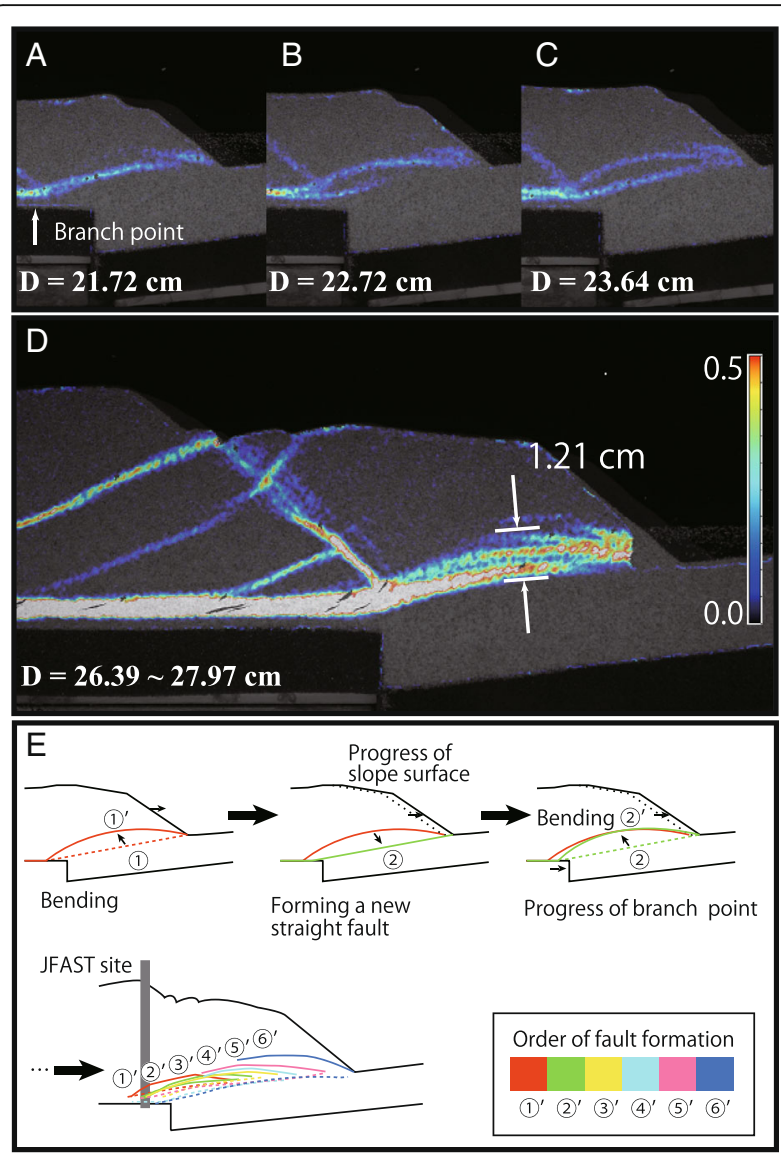

Fig. 5 Schematics of dancing. a-c Continuous deformation of dancing. The white arrow indicates the branch point (McClay 1992). When the fault grows longer, it evolves into an anastomosing structure, as observed in stage 3 of Fig. 4. $\mathbf{d}$ The fault activity during dancing and the accumulated shear strain (100 s=20 image frames) of EXP 2 during the stage 3 . The accumulated shear strain becomes larger in the order from blue to red in the color reference. Incremental shear strain indicates relative, not absolute, quantity. e Schematic diagrams of the fault dancing with the comparison of the JFAST site. Convex upward deformation of the fault is gradual, then the fault abruptly passes down to become a straight fault

moved toward the trenchward side. As the deformation continued, the length of T2 became longer and the branch point stopped at the step of the half graben $(24.14 \mathrm{~cm}$ of shortening). The deformation schematics are similar in this stage, but the shortcut fault has a form in which multiple faults are continuous.

\section{Discussion}

Effect of the dancing phenomenon

The fault dancing in stage 3 of EXP 2 helps form a thick sheared zone, which resembles an anastomosing structure (Fig. $5 \mathrm{a}-\mathrm{c}$ ). In order to examine this feature in detail, we have calculated the accumulated total strain during $1.7 \mathrm{~cm}$ of shortening in $100 \mathrm{~s}$ (Fig. 5d). The results show that the average thickness of the 'non-dancing' fault is approximately 
$0.35 \mathrm{~cm}$ in the reference experiment, whereas the thickness of the shear zone with the dancing fault is approximately $1.21 \mathrm{~cm}$. This clearly suggests that dancing has the effect of thickening the shear zone. We summarized the timeline of the fault dancing and the resulting structure (Fig. 5e). The thickness of the shear zone has been used for the estimation of fault displacement using the empirical thickness-displacement law, and the fault displacement has been further used to estimate the energy that can be released by the fault (e.g., Kim and Sanderson 2005). Our results, however, suggest that such calculations without considering the fault dancing effect may overestimate the displacement. Concerning the damaged structure, fault dancing could be a critical aspect of the formation of mélange. In Fig. 5e, the thrust activities follow in the order (1), (2), (3), and so on. The structure is sheared/deformed by activity (1) and suffers further deformation by the new thrust activity (2). These deformations are continuous with new thrust activities following repeatedly. Thus, it is expected that the final structure has been the complex suffered repeated shearing with a constant width. However, the experiments in this study do not include the effect of dewatering under the compaction.

\section{Mechanism of fault dancing}

In order to examine the mechanism of fault dancing, we divided these half-graben structures into two geometrical elements: (1) the gap in the top basement horizon; and (2) tilting of the top basement horizon. For the effect of the step, there are several studies of subduction of convex geometry in the basement, e.g., ridge and seamount subduction, but few previous studies are known of concave geometries, e.g., graben subduction. The features immediately following a seamount subduction may be used as an analogy of concave subduction, since the décollement extends down from the top of the seamount to the basement level, where the fault activity continues longer than others (Morgan and Bangs 2017). In our experiments, this feature may correspond to the longer activity of $\mathrm{T} 2$ at stage 3 , suggesting that the step forming a concave geometry can generate longer fault life. Morgan and Bangs 2017, however, do not report the fault dancing feature. This suggests that the second geometrical element, change in dip of the top basement, may control the fault dancing. In addition, the friction along the décollement in this experiment suddenly changed around the half-graben structure. The friction along the décollement was low at the top surface of the basement covered by a Teflon sheet, but the décollement friction in the half-graben was high, i.e., in sand. This change of the friction of décollement connects to such the discussion of varying down-décollement strength controls wedge growth versus propagation (Bose et al. 2015).

\section{Interpretation of the structure of the Japan Trench}

The JFAST drilling project confirmed the presence of a thick $(\sim 100 \mathrm{~m})$ deformation zone just above the plate boundary fault in a location with a relatively small magnitude of offset $(\sim 3.2 \mathrm{~km})$. The thickness of the well-developed deformation zone is approximately $100 \mathrm{~m}$, and that of the fault zone is approximately $7 \mathrm{~m}$ (Kirkpatrick et al. 2015). In this study, the fault thickness in the experiments was generally $0.35 \mathrm{~cm}$, but the fault dancing produced a shear zone that was four times thicker, $1.12 \mathrm{~cm}$ (Fig. 5). Since $1.12 \mathrm{~cm}$ in the experiment corresponds to ca. $280 \mathrm{~m}$ in the natural scale, which can be compared with the natural thickness of the deformation zone, such a thick shear zone may be explained by the mechanism of fault dancing.

\section{Conclusions}

We have conducted experiments focusing on half-graben subduction and found a dancing feature that is a new pattern of fault development. The fault dancing can thicken the sheared zone in a relatively short time scale (approximately 0.03 million years). Our results suggest the following:

1) It is important to consider the mechanisms that generate deformation zone thickness when estimating displacement and total energy dissipation, as wide shear zones can be produced even with a limited slip.

2) The strain distribution suggests that the fault dancing mechanism may be a process that can generate tectonic mélange formation.

3) Fault dancing may explain the presence of both a relatively thin plate boundary décollement within a relatively thick deformation zone observed in the Japan Trench.

\section{Abbreviations}

DIC: Digital image correlation; JFAST: Japan Trench Fast Drilling Project, Integrated Ocean Drilling Program, Expedition 343 and 343T

\section{Acknowledgements}

We thank Jin-Hisn Changm, Natsumi Okutsu, Ryota Hasegawa, and Kotaro Fujita for their great assistance in our experiments. We also thank the members of the Department of Ocean Floor Geoscience of the Atmosphere and Ocean Research Institute for having greatly improved our motivation in conducting the research. Thanks are extended to the editors and two anonymous reviewers for their constructive comments.

\section{Funding}

HK was supported by the Sasakawa Scientific Research Grant from the Japan Science Society. YY is supported partly by JSPS KAKENHI Grant Number JP15H05717 and JSPS KAKENHI Grant Number 17K05687. JA is supported by JSPS KAKENHI Grant Number 18H03732.

Availability of data and materials

Please contact author for data requests.

Authors' contributions

HK proposed the topic, conceived and designed the study, carried out the experimental and analytical study, and wrote the manuscript. YY provided 
the experimental equipment, guided the basic operation, discussed the results, and wrote the manuscript. $A O$ helped each time with the operation of the experiment and discussed the results. $A B$ discussed the research from the viewpoint of numerical experiments. AY collaborated with the corresponding author in the preparation of the manuscript. JA is HK's supervisor, and discussed the results, supported HK via a grant mainly to attend a conference for the development of this research, and wrote the manuscript. All authors read and approved the final manuscript.

\section{Authors' information}

HK is a PhD student and specializes in structural geology, marine geology, and tectonic geomorphology of subduction zones. $Y Y$ is the head of the Research and Development Center and specializes in petroleum geology, structural geology, geophysical exploration, and drilling science of subduction zones. $\mathrm{AO}$ specializes in marine geology of subduction zones. $\mathrm{AB}$ is a researcher specialized in the mechanics of geological structures. AY is an Associate Professor and specializes in marine geology, structural geology, and chemical geology of subduction zones. JA is an Associate Professor and specializes in marine geology of subduction zones.

\section{Competing interests}

The authors declare that they have no competing interests.

\section{Publisher's Note}

Springer Nature remains neutral with regard to jurisdictional claims in published maps and institutional affiliations.

\section{Author details}

${ }^{1}$ Atmosphere and Ocean Research Institute, The University of Tokyo, 5-1-5 Kashiwanoha, Kashiwa-shi, Chiba 277-8564, Japan. ²Department of Natural Environmental Studies Division of Environmental Studies, Graduate School of Frontier Sciences, The University of Tokyo, 5-1-5 Kashiwanoha, Kashiwa-shi, Chiba 277-8564, Japan. ${ }^{3} J a p a n$ Agency for Marine-Earth Science and Technology, 3173-25 Showa-machi Kanazawa, Yokohama 236-0001, Japan. ${ }^{4}$ Faculty of Science and Technology, Kochi University, 2-5-1 akebono-cho, Kochi-shi, Kochi 780-8520, Japan.

Received: 2 April 2018 Accepted: 11 October 2018 Published online: 01 November 2018

\section{References}

Adam J, Urai JL, Wieneke B, Oncken O, Pfeiffer K, Kukowski N, Lohrmann J, Hoth S, van der Zee W, Schmatz J (2005) Shear localisation and strain distribution during tectonic faulting - new insights from granular-flow experiments and high-resolution optical image correlation techniques. J Struct Geol 27(2):283-301

Bilek SL, Lay T (2002) Tsunami earthquakes possibly widespread manifestations of frictional conditional stability. Geophys Res Lett 29(14). https://doi.org/10. 1029/2002GL015215

Bose S, Saha P, Mori JJ, Rowe C, Ujiie K, Chestere FM, Conin M, Regalla C, Kameda J, Toy V, Kirkpatrick J, Remittii F, Moore JC, Wolfson-Schwehrk M, Nakamural Y, Gupta A (2015) Deformation structures in the frontal prism near the Japan Trench: Insights from sandbox models. J Geodyn 89:29-38

Chester FM, Mori JJ, Toczko S, Eguchi N, Kido Y, Saito S, Sanada Y, Anderson L, Behrmann JH, Bose S (2012) Integrated Ocean Drilling Program Expedition 343/343T Preliminary Report, Japan Trench Fast Drilling Project (JFAST). In: Integrated Ocean Drilling Project Preliminary Report, 343

Chester FM, Rowe C, Ujiie K, Kirkpatrick J, Regalla C, Remitti F, Moore JC, Toy V, Wolfson-Schwehr M, Bose S, Kameda J, Mori JJ, Brodsky EE, Eguchi N, Toczko S, Expedition 343 and 343T Scientists (2013) Structure and composition of the plate-boundary slip zone for the 2011 Tohoku-Oki earthquake. Sci 342(6163):1208-1211

DeMets C, Gordon RG, Argus DF (2010) Geologically current plate motions. Geophys J Int 181(1):1-80

Dotare T, Yamada Y, Adam J, Hori T, Sakaguchi H (2017) Initiation of a thrust fault revealed by analog experiments. Tectonophys 684:148-156

Fujiwara T, Kodaira S, No T, Kaiho Y, Takahashi N, Kaneda Y (2011) The 2011 Tohoku-Oki earthquake: displacement reaching the trench axis. Sci 334(6060):1240

Graveleau F, Malavieille J, Dominguez S (2012) Experimental modelling of orogenic wedges: a review. Tectonophys 538:1-66
Kim YS, Sanderson DJ (2005) The relationship between displacement and length of faults: a review. Earth-Sci Rev 68(3):317-334

Kirkpatrick JD, Rowe CD, Ujiie K, Moore JC, Regalla C, Remitti F, Toy V, WolfsonSchwehr M, Kameda J, Bose S (2015) Structure and lithology of the Japan Trench subduction plate boundary fault. Tecton 34(1):53-69

Kodaira S, No T, Nakamura Y, Fujiwara T, Kaiho Y, Miura S, Takahashi N, Kaneda Y, Taira A (2012) Coseismic fault rupture at the trench axis during the 2011 Tohoku-oki earthquake. Nat Geosci 5(9):646-650

LaVision (2012) Product-Manual for Davis 8.0 StrainMaster. LaVision Gmbh, Gottingen

Lohrmann J, Kukowski N, Adam J, Oncken O (2003) The impact of analogue material properties on the geometry, kinematics, and dynamics of convergent sand wedges. J Struct Geol 25(10):1691-1711

McClay K (1992) Glossary of thrust tectonics terms. In: McClay K (ed) Thrust tectonics. Springer, Berlin

Moeremans R, Singh SC, Mukti M, McArdle J, Johansen K (2014) Seismic images of structural variations along the deformation front of the AndamanSumatra subduction zone: implications for rupture propagation and tsunamigenesis. Earth Planet Sci Lett 386:75-85

Moore GF, Shipley TH, Stoffa PL, Karig DE, Taira A, Kuramoto S, Tokuyama H, Suyehiro K (1990) Structure of the Nankai Trough accretionary zone from multichannel seismic reflection data. J Geophys Res Solid Earth 95(B6): $8753-8765$

Morgan JK, Bangs NL (2017) Recognizing seamount-forearc collisions at accretionary margins: insights from discrete numerical simulations. Geol 45(7):635-638

Nakamura Y, Kodaira S, Miura S, Regalla C, Takahashi N (2013) High-resolution seismic imaging in the Japan Trench axis area off Miyagi, northeastern Japan. Geophys Res Lett 40(9):1713-1718

Scholz CH (1998) Earthquakes and friction laws. Nat 391(6662):37

Sun T, Wang K, Fujiwara T, Kodaira S, He J (2017) Large fault slip peaking at trench in the 2011 Tohoku-oki earthquake. Nat Commun 8:14044

Ujiie K, Tanaka H, Saito T, Tsutsumi A, Mori JJ, Kameda J, Brodsky EE, Chester FM, Eguchi N, Toczko S (2013) Low coseismic shear stress on the Tohoku-Oki megathrust determined from laboratory experiments. Sci 342(6163):1211-1214

Yamada Y, Baba K, Miyakawa A, Matsuoka T (2014) Granular experiments of thrust wedges: insights relevant to methane hydrate exploration at the Nankai accretionary prism. Mar Pet Geol 51:34-48

\section{Submit your manuscript to a SpringerOpen ${ }^{\circ}$ journal and benefit from:}

- Convenient online submission

- Rigorous peer review

- Open access: articles freely available online

High visibility within the field

- Retaining the copyright to your article

Submit your next manuscript at $\boldsymbol{\text { springeropen.com }}$ 